\title{
Pretreatment neutrophil-to-lymphocyte ratio and Mean Platelet Volume in castration-resistant prostate cancer patients treated with first-line docetaxel
}

\section{Barbaros Başeskioğlu}

\section{Eskisehir Acibadem Hospital}

Berna Bozkurt Duman ( $\square$ berboz@hotmail.com )

University of Health Sciences Adana City Education and Research Hospital

\section{Bülent Yıldız}

Eskisehir Osmangazi Universitesi

\section{Timuçin Çil}

University of Health Sciences Adana City Education and Research Hospital

\section{Murat Dinçer}

Eskisehir Osmangazi Universitesi

Ertuğrul Bayram

Agrı Government Hospital

\section{Research article}

Keywords: Castration-resistant disease, Prostate Cancer, Mean Platelet Volume,

Posted Date: August 31st, 2019

DOI: https://doi.org/10.21203/rs.2.13801/v1

License: (c) (i) This work is licensed under a Creative Commons Attribution 4.0 International License.

Read Full License 


\section{Abstract}

Background:Patients who have evidence of disease progression (eg, increase in serum prostate-specific antigen [PSA], new metastases, progression of existing metastases) while being managed with androgen deprivation therapy (ADT) are considered to have castration-resistant disease. Docetaxel $(75 \mathrm{mg} / \mathrm{m} 2)$ given every three weeks in combination with daily prednisone ( $5 \mathrm{mg}$ twice a day) significantly prolonged overall survival compared with mitoxantrone plus prednisone in the TAX 327 phase III trial [3]. Based upon those results, docetaxel plus prednisone has become the standard initial regimen when chemotherapy is indicated for CRPC Methods: Inflammation-based markers, such as the Neutrophile/Lymphocyte Ratio (NLR), are widely available and inexpensive measurements that are easy to integrate into pretreatment evaluation. Mean platelet volume (MPV) is a marker of activated platelets is associated some types of cancer including ovarian, gastric cancer. We retrospectively evaluated the predictive impact of neutrophil-lymphocyte ratio (NLR) and MPV as a marker for in men with progressive metastatic castration resistant prostate cancer (mCRPC) following docetaxel.Results: A significant correlation was not observed between NLR and PSA response. A significant correlation was not also observed between MPV and PSA response.There no correlation was found between MPV and NLR with total PSA level and response (p:0.355, p:0.673 respectively)Conclusion: . In our study; We didn't show any correlation between MWP level, NLR ratio and response to Docetaxel therapy A significant correlation was not also observed between NLR, MPV and PSA response.

\section{Background}

The disease progression after androgen deprivation therapy (ADT) by surgical or medical orchiectomy is defined as Castration-resistant prostate cancer (CRPC). There are several strategies including cabazitaxel, abiraterone, enzalutamide and sipuleucel-T have been approved for therapy of these men and several other drugs including novel androgen-modulating approaches[1,2]. Taxanes are the only cytotoxic chemotherapy agents that have significantly prolonged overall survival in clinical trials in men with CRPC. Docetaxel chemotherapy is one of the choices of the therapy. Docetaxel $\left(75 \mathrm{mg} / \mathrm{m}^{2}\right)$ given every three weeks in combination with daily prednisone ( $5 \mathrm{mg}$ twice a day) significantly prolonged overall survival compared with mitoxantrone plus prednisone in the TAX 327 phase III trial [3]. Based upon these results, docetaxel plus prednisone has become the standard initial regimen when chemotherapy is indicated for CRPC. [3]

Serial measurement of serum prostate-specific antigen (PSA) during hormonal therapy is the primary approach for monitoring response to systemic hormonal treatment for men with the rising PSA or disseminated metastases. The frequency of monitoring is influenced by the likelihood of disease progression. [4] The testosterone suppression should be checked when PSA level rises.

Many studies showed the importance of activated platelets in cancer progression and metastasis.[5,6] There are several cancer types like gastric cancer, ovarian cancer, lung cancer, colon cancer and breast cancer in these types of cancers.[7-11] 
The main aim of our retrospective study was to assess the prognostic value, in terms of response to the therapy in the correlation with NLR and MPV, in patients treated with first-line docetaxel for CRPC.

\section{Methods}

This retrospective study examined the records of 78 patients the records of 78 patients with a new diagnosis of metastatic castrate resistance prostate adenocarcinoma who received three weekly docetaxel with $5 \mathrm{mg}$ prednisone twice daily. Patient demographics have been summarised in Supplementary Table 1.

For the men who develop CRPC as described as, serum levels of testesterone below $50 \mathrm{ng} / \mathrm{ml}$ under ADT treatment. Castration resistance was described as biochemical and radiologic progression after androgen deprivation therapy. Catrate levels of testesterone below $50 \mathrm{ng} / \mathrm{ml}$ was maintened by contuining LHRH agonist while Docetaxel therapy is applied. All of the patients'treatment responses were detected by bone scintigraphy, torachal and abdominal tomography with total PSA and testesteron level. For radiographic evaluation

(i.e., bone scan, pelvic MRI or CT), patients were examined at the start and after 3 or 6 cycles of chemotherapy.Disease progression was defined as an increase of PSAlevel $\geq 25 \%$ relative to the pretreatment PSA baseline with radiologic assesment. And (or) radiological progression according to the recommendations of Prostate Cancer Work Group-2 (PCWG-2). For follow-up, PSA and ALP levels were examined once a month and radiographic evaluation were performed every 3 months. Patients'hemogram and biochemical measurements with liver and renal function tests every cycle.

NLR was calculated by dividing absolute neutrophil count by absolute lymphocyte count measured in peripheral blood. The patients were in good performance status (KPS $\geq 70$ ). MPV levels and NLR were divided due to response type.

OS was defined as the time from the start of chemotherapy from the start of the docetaxel treatment to death or the date of last follow-up.

\section{Results}

Median age at diagnosis was 78 years (range 47-88), Median follow-up time (reverse Kaplan-Meier method) was 39 months (range 31-52 months). (Figure 1). The mean MPV level was 8.121+/1.0654(min6.3-max10.4) in patients with stabil disease, the mean MPV level was 8,411+/-1,6789(min:5.3max:11.2) in responsive patients, the mean MPV level was 8.0074+/-1,6789 (min:5.3-max:10.6) in progressive disease.

The mean N/L ratio level was 3.6614+/- 2.32793(min1-max9.67) in patients with stabil disease, the mean N/L ratio level was 3,8356+/-3.04520(min:0,84-max:15.5) in responsive patients, the mean MPV level was 3,3714+/-1,7986 (min:1.47-max:8.57). 
The NLR ratio of patients have not statistically significant difference between each groups $p=0.355$. The MPV ratio is not significantly significant for prediction of docetaxel chemotherapy in all patients groups.(p: 0.673)

A significant correlation was not observed between NLR and PSA response. A significant correlation was not also observed between MPV and PSA response.There no correlation was found between MPV and NLR with total PSA level and response (p:0.355, p:0.673 respectively)

\section{Discussion}

Most of the metastatic prostate cancer patients initially respond to hormonal therapy for a median duration of 18 months, they eventually develop castration resistant prostate cancer (CRPC).[12]

Two large randomized phase III clinical trials (TAX 327 and SWOG 99-16) showed a significant survival benefit of docetaxel-based chemotherapy in patients

with CRPC, and established its status as the first-line treatment regimen [13,14]. Based upon those results of TAX 327 docetaxel plus prednisone has become the standard initial regimen when chemotherapy is indicated for CRPC

Serial measurement of serum prostate-specific antigen (PSA) during hormonal therapy is the primary approach for monitoring response to systemic hormonal treatment for mean with a rising PSA or disseminated metastases. The frequency of monitoring is influenced by the likelihood of disease progression. Total PSA is good predictor for measuring treatment response.[15]

More than 60 studies showed the prognostic importance of NLR. Prostate cancer is one of these cancers[16-19] Several prognostic factors were defined fort he men who treated with docetaxel.[20-22]

The mechanisms underlying the association of MPV is currently unclear. There are many studies which showed the stimulator of cell proliferation/transformation in prostate cancer for the platelet-derived growth factor (PDGF) proteins. [23]

PDGF alpha-receptor activation is associated with bone metastases in CRPC . In prostate cancer mice targeting PDGF alpha-receptor effectively counteracts skeletal metastases.[24] 
These data are also in agreement with MPV is an early marker of activated platelets.[25]

Wang et al. have reported in their metaanalysis that elevated NLR predicted a poor OS and PFS in patients with CRPC. The NLR could serve as an indicator of the efficacy of the treatment of CRPC. Most of the studies like this study showed the prognostic factor of NLR.[26]

Indeed, some drugs, infections, many concurrent conditions can effect neutrophil and lymphocyte counts and MPV levels. Not only these parameters but the combination with other parameters can be useful for evaluation of therapeutic response.

\section{Conclusions}

We have investigated the predictive impact of the NLR and MPV for detecting Docetaxel response in men receiving first-line chemotherapy with docetaxel for $\mathrm{MCRPC}$. We show that there are no correlation between pretreatment levels of NLR and MPV with Docetaxel response .Men with an elevated pretreatment NLR of $>3.0$ were found to be at higher risk of death after adjusting for other prognostic variables due to some studies But these parameters are not predictive for docetaxel response. context of additional therapies for advanced prostate cancer. There are no study about MPV importance for docetaxel response. In our study; We didn't show any correlation between MWP level, NLR ratio and response to Docetaxel therapy A significant correlation was not also observed between NLR, MPV and PSA response.

\section{Abbreviations}

PSA: Prostate-specific antigen

ADT: Androgen deprivation therapy

MPV: Mean platelet volüme

CRPC: Castration resistant prostate cancer

NLR: Neutrophile lymphocyte ratio

\section{Declarations}


Acknowledgements

Not applicable.

Funding

There was no funding provided for this study.

Author information

Affiliations

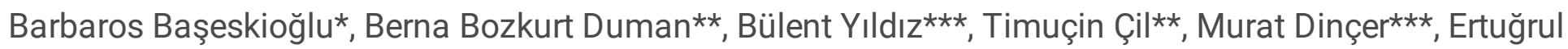
Bayram**.

*Eskişehir Acıbadem Hospital Department of Urology

**Univeristy of Health Sciences, Adana City Education and Research Hospital Department of Medical Oncology

***Eskişehir Osmangazi Medical Faculty, Department of Medical Oncology

\section{Authors}

Contributions

$\mathrm{BB}, \mathrm{BY}, \mathrm{EB}, \mathrm{TC}, \mathrm{MD}$ did the data entry, statistical analysis and interpretation of the data and was a major contributor in writing the manuscript. BBD coordinated the collection of data from patients and contributed and approved the final manuscript. BB participated in the design of the study, reviewed the results and was a major contributor to writing the manuscript. All authors read and approved the final manuscript.

Corresponding author

Correspondence to Berna Bozkurt Duman

Ethics declarations

Ethics approval and consent to participate

Ethical Improvement : institutional ethical comitte( Adana City Hospital Ethical Comitte) approved this study.(Date: 27.02.2019 Decision No: 385) Patient written informed consent to review their medical records was not obtained it was waived by the ethics committee due to the study style as retrospective series. Some of the patients were died when included to the study and these patients were analysed 
retrospectively.Patients datas confidentiality hidden by study team and the patients names were hidden during the analysis and compliance with the Declaration of Helsinki.

Consent for publication

The results presented in this paper have not been published previously in whole or part.

Competing interests

The authors declare that they have no competing interests.

\section{References}

1-Loblaw DA, Walker-Dilks C, Winquist E, Hotte SJ. Systemic therapy in men with metastatic castration-resistant prostate cancer: a systematic review.Clin Oncol (R Coll Radiol) 2013; 25: 406-30

2-Tannock IF, de Wit R, Berry WR et al. Docetaxel plus prednisone or mitoxantrone plus prednisone for advanced prostate cancer. N Engl J Med 2004; 351: $1502-1512$.

3-Berthold DR, Pond GR, Soban F, et al. Docetaxel plus prednisone or mitoxantrone plus prednisone for advanced prostate cancer: updated survival in the TAX 327 study. J Clin Oncol 2008; 26:242.

4-Virgo KS, Basch E, Loblaw DA, et al. Second-Line Hormonal Therapy for Men With Chemotherapy-Naïve, Castration-Resistant Prostate Cancer: American Society of Clinical Oncology Provisional Clinical Opinion. J Clin Oncol 2017.

5-Bambace NM, Holmes CE. The platelet contribution to cancer progression. J Thromb Haemost. 2011;9:237-49. 
6-Goubran HA, Stakiw J, Radosevic M, Burnouf T. Platelet cancer interactions. Semin Thromb Hemost. 2014;40:296305.

7-Kilincalp S, Ekiz F, Basar O, Ayte MR, Coban S, Yilmaz B, Altinbas A, Basar N, Aktas B, Tuna Y, Erbis H, Ucar E, Erarslan E, et al. Mean platelet volume could be possible biomarker in early diagnosis and monitoring of gastric cancer. Platelets. 2014;25:592-4.

8-Kemal Y, Demirag G, Ekiz K, Yucel I. Mean platelet volume could be a useful biomarker for monitoring epithelial ovarian cancer. J Obstet Gynaecol. 2014;34:5158.

9-Kumagai S, Tokuno J, Ueda Y, Marumo S, Shoji T, Nishimura T, Fukui M, Huang CL. Prognostic significance of preoperative mean platelet volume in resected non-smallcell lung cancer. Mol Clin Oncol. 2015;3:197-201.

10-Li JY, Li Y, Jiang Z, Wang RT, Wang XS. Elevated mean platelet volume is associated with presence of colon cancer. Asian Pac J Cancer Prev. 2014;15:10501-4.

11-Gu M, Zhai Z, Huang L, Zheng W, Zhou Y, Zhu R, Shen F, Yuan C. Pre-treatment mean platelet volume associates with worse clinicopathologic features and prognosis of patients with invasive breast cancer. Breast Cancer. 2015;23:752-60.

12-Feldman BJ, Feldman D. The development of androgen independent prostate cancer. Nat Rev Cancer 2001(1):34-45

13-Petrylak DP, Tangen CM, Hussain MH et al (2004) Docetaxel and estramustine compared with mitoxantrone and prednisone for advanced refractory prostate cancer. $\mathrm{N}$ Engl J Med

351(15):1513-1520 
14- Tannock IF, de Wit R, Berry WR et al (2004) Docetaxel plus prednisone or mitoxantrone plus prednisone for advanced prostate cancer. N Engl J Med 351(15):1502-1512

15-Virgo KS, Basch E, Loblaw DA, et al. Second-Line Hormonal Therapy for Men With ChemotherapyNaïve, Castration-Resistant Prostate Cancer: American Society of Clinical Oncology Provisional Clinical Opinion. J Clin Oncol 2017; :JCO2017728030.

16-Templeton AJ, McNamara MG, Vera-Badillo FE, et al. Prognostic role of neutrophil to lymphocyte ratio (nlr) in solid tumors: a systematic review and meta-analysis. J Natl Cancer Inst. 2014:106;

dju124

17-Guthrie GJ, Charles KA, Roxburgh CS, Horgan PG, McMillan DC, Clarke SJ. The systemic inflammationbased neutrophil-lymphocyte ratio: experience in patients with cancer. Crit Rev Oncol Hematol.2013;88:218-230.

18-Shafique K, Proctor MJ, McMillan DC, Qureshi K, Leung H, Morrison DS. Systemic inflammation and survival of patients with prostate cancer: evidence from the Glasgow Inflammation Outcome Study. Prostate Cancer Prostatic Dis. 2012;15:195-201.

19-Sonpavde G, Pond GR, Armstrong AJ, et al. Prognostic impact of the neutrophil-to-lymphocyte ratio in men with metastatic castration-resistant prostate cancer. Clin Genitourin Cancer. 2014; S15587673:00054-00058.

20-Emrich LJ, Priore RL, Murphy GP, Brady MF. Prognostic factors in patients with advanced stage prostate cancer. Cancer Res 1985; 45: 5173-9.

21-Halabi S, Small EJ, Kantoff PW et al. Prognostic model for predicting survival in men with hormone-refractory metastatic prostate cancer. 
J Clin Oncol 2003; 21: 1232-7

22-Smaletz O, Scher HI, Small EJ et al. Nomogram for overall survival of patients with progressive metastatic prostate cancer after castration. J Clin

Oncol 2002; 20: 3972-82

23-Ustach CV, Taube ME, Hurst NJ, et al A potential oncogenic activity of platelet-derived growth factor d in prostate cancer progression. Cancer Res,(2004) 64, 1722-9.

24-Russell MR, Liu Q, Lei H, Kazlauskas A, Fatatis A. The alpha-receptor for platelet-derived growth factor confers bone-metastatic potential to prostate cancer cells by ligand- and dimerization-independent mechanisms. Cancer Res(2010), 70, 4195-4203.

25- Mezouar S, Frere C, Darbousset R, et al. Role of platelets in cancer and cancer-associated thrombosis: Experimental and clinical evidences. Thromb Res(2016), 139, 65-76

26-Wang Z, Peng S, Xie H, Guo L, Jiang N, Shang Z, Niu Y. Neutrophil-lymphocyte ratio is a predictor of prognosis in patients with castration-resistant prostate cancer: a meta-analysis. Cancer Manag Res. 2018 Sep 17;10:3599-3610.

\section{Tables}

Table 1: Patients Characteristics

Patients Characteristics

n:78

Median age:

78 years (range $47-88$ ),

Visseral metastasis

64(82.1\%)

Bone metastasis

$14(18 \%)$

Page 10/11 


\section{Median NLR}

Stable

8.121+/- 1.0654(min6.3-max10.4)

Responsive

8,411+/-1,6789(min:5.3-max:11.2)

Progressive

8.0074+/-1,6789 (min:5.3-max:10.6) .

Median MPV

Stable

3.6614+/- 2.32793 (min 1-max9.67)

Responsive

3,8356+/-3.04520 (min:0,84-max:15.5)

Progressive

3,3714+/-1,7986 (min:1.47-max:8.57).

Figures

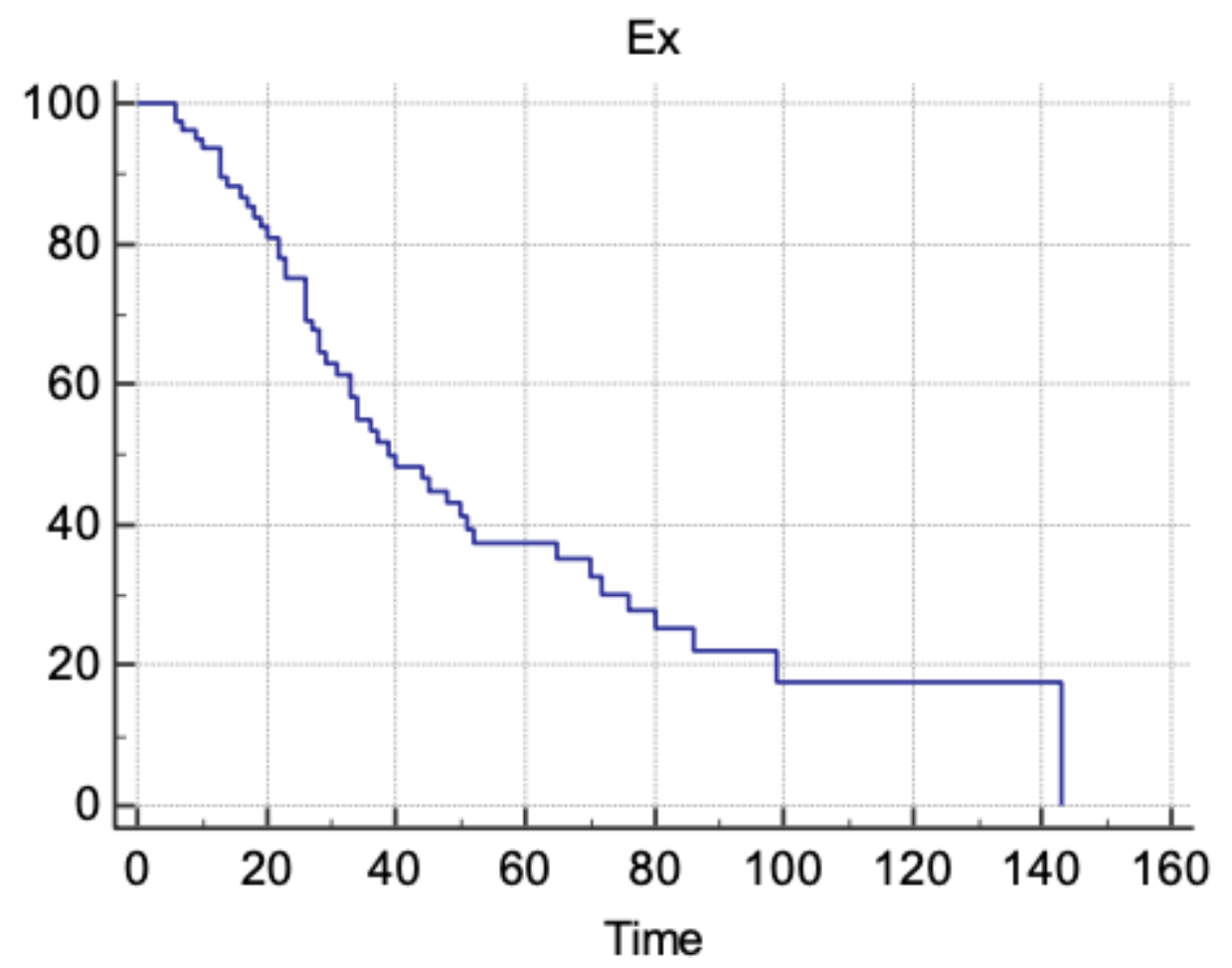

Figure 1

Median OS 39 months (\%95 Cl 31-52 months) 